\title{
Supervised Exercise Patterns among Diabetic and Non-diabetic Portuguese Adults
}

\author{
1,2 Maria Esteves*, ${ }^{3,4}$ Ana Gouveia, ${ }^{5,6}$ Ricardo Rodrigues, ${ }^{5,6}$ Paulo Pinheiro, ${ }^{1,2}$ Rui Bras, \\ ${ }^{1}$ Kelly O'Hara, ${ }^{5,6}$ Paulo Duarte \\ ${ }^{1}$ Sport Sciences Department, University of Beira Interior, Covilhã, Portugal. ${ }^{2}$ CIDESD (Research Centre \\ in Sports Sciences, Health Sciences and Human Development), Covilhã, Portugal. ${ }^{3}$ Faculty of Health \\ Sciences, University of Beira Interior, Covilhã, Portugal. ${ }^{4}$ IBEB (Institute of Biophysics and Biomedical \\ Engineering), University of Lisbon, Lisboa, Portugal. ${ }^{5}$ Business and Economics Department, University of \\ Beira Interior, Covilhã, Portugal. ${ }^{6} \mathrm{NECE}$ (Research unit in Business Sciences), Covilhã, Portugal.
}

Submitted 11 March 2019; Accepted in final form 13 May 2019.

\begin{abstract}
Background. Physical activity (PA) is a keystone of diabetes management, but although self-exercise is beneficial, supervised exercise (SE), adapted to individual characteristics, and is more effective. Objectives. The main research goal is to compare SE patterns among diabetic and non-diabetic Portuguese adults. Methods. A total of 484 participants (85 diabetics, 399 non-diabetics), aged 41-90 years old (mean=58.9; $\mathrm{SD}=11.9$ ) were interviewed. PA level was assessed using short form of the International Physical Activity Questionnaire. Attendance in different SE programs was evaluated across three kinds of PA programs providers: gym/health-clubs; swimming pools and other club/ sports facilities. Itens like Barriers to Exercise; Intention to participate; Importance of the structure and PA information sources were also evaluated. Independent t-tests were used to examine the difference between the group means, and Levene's test was used to check the homokedasticity of the groups' variances. Results. PA level of diabetics (32\% low; $25 \%$ moderate; $44 \%$ high) and non-diabetics (29\% low; 33\% moderate; 39\% high) display no differences. $90 \%$ of diabetics do not attend SE. The main barrier for diabetics' non-participation is the perception that the exercise is not adequate to their health. Doctors are the preferred information source for diabetics and they rely less on information provided by the Internet, with may impair on-line campaigns. Conclusion. Promoting exercise in diabetics should shift the focus from "promoting physical activity" to "promoting SE".
\end{abstract}

\section{KEY WORDS: Health Promotion, Exercise, Diabetes}

\section{INTRODUCTION}

The 2016 Position Statement of the American Diabetes Association reinforces that Physical Activity (PA) is critical for individuals with diabetes, since exercise improves blood glucose control in type 2 diabetes, reduces cardiovascular risk factors, contributes to weight loss and improves well-being (1). Nevertheless, the sedentary lifestyle continues to increase among the diabetic population, despite extensive PA promotion campaigns $(2,3)$.

A keystone of diabetes prevention and management is the person's motivation to embrace a change in lifestyle, with primary emphasis in PA and diet $(4,5)$. PA alone improves glucose tolerance and whole-body insulin sensitivity (6). Despite the salutary

*. Corresponding Author:

Maria Esteves, $\mathrm{PhD}$

E-mail: desteves@ubi.pt 
effects of exercise on glycaemic control, people with diabetes do not exercise as much as nondiabetic individuals, possibly due to both behavioural (fear of injury as well as other diabetes-related concerns) and functional (impairments in both maximal and submaximal exercise performance) factors $(3,4)$.

Exercise presents significant benefits but also some risks in diabetes management (7). For example hypoglycemia, complications in the musculoskeletal system, cardiovascular risk, and feet neuropathy. Therefore, most diabetics can engage in PA without following any particular instructions or rules, but it is, however, essential to receive guidance (7). Diabetics should, therefore, participate in supervised exercise (SE) programs where they can exercise with minimum risks. Some authors emphasize that SE programs are preferable to patients with Diabetes, although the promotion of autonomous exercise is more feasible and should also be offered to diabetics (8). In fact, a meta-analysis of small-sized studies showed that SE is effective in improving cardiorespiratory fitness, glycaemic control and other cardiovascular risk factors (9).

The adequate "dose" of exercise as a preventive treatment to diabetics needs more research, since exercise should provide enough stimulus to improve critical clinical endpoints (e.g. insulin sensitivity and beta-cell dysfunction) but not necessarily avoid the risk of future complications (e.g. nephropathy, neuropathy, and retinopathy and macrovascular disease) (10). This fact means that current exercise recommendation for diabetics- 150 minutes of moderate to vigorous intensity aerobic exercise, spread out over at least three days during the week is a starting point, but the intensity, duration, and type of exercise should be customized to each person, better achieved under SE (1).

Grace et al. (11) performed a meta-analysis and concluded that higher intensities promote better responses regarding diabetes management. These higher intensities should be performed under professional supervision.

Based on these findings it seems clear, that exercise is an adjuvant therapy for diabetics, but its effectiveness depends on how it is performed, what causes SE to be more effective. Despite this evidence, literature refers that people with diabetes are often unwilling to participate in exercise programs due to specific barriers and the absence of adequate information to persuade patients and providers to take concrete actions and modify the sedentary behaviour (2). These findings stress the need for better education and more information regarding the benefits of SE programs specially tailored for people with diabetes.

From the above reasoning, it can be established that PA is an essential aspect in the management of diabetes, being much more effective if performed with adequate mode, intensity, duration and frequency, requiring personalized monitoring and supervision. In order to promote the participation of diabetics in structured and supervised activities, the motivations and causes of non-participation that are specific to the diabetic population must be understood. Therefore, it is necessary to compare diabetics with non-diabetics regarding participation in SE programs to evaluate if there are differences that allow the elaboration/revision of PA programs that accomplish a higher attendance from diabetics.

The main objective of this research is to compare SE patterns among diabetic and nondiabetic Portuguese adults. The specific objectives are the comparison between diabetics and non-diabetics regarding: (i) PA level; (ii) attendance in different SE programs; (iii) PA information sources; (iv) intention to participate in different types of pre-defined programs and (v) the perceived importance of the characteristics of the structure that hosts the exercise program.

The findings are valuable to support the development of a strategy that will lead diabetics to become more active but mainly to engage in supervised intense PA activities. This strategy is vital for diabetics since by adhering to a personalized exercise and supervised by accredited professionals can simultaneously increase the benefits of PA in diabetes management and also in improving physical fitness.

\section{MATERIAL AND METHODS}

Participants. Following the approval of the Scientific Committee of the Ph.D. in Sports Science approval, from the University of Beira Interior, and according to the Declaration of Helsinki, 484 participants aged between 41 to 90 years old (mean $=58.9 ; \mathrm{SD}=11.9$ ) were included in this study. Participants were recruited in public places, in different across all regions of Portugal, 
in cities and rural villages. Participants were completely free to participate in the study, after the presentation of researchers' affiliation, investigation goals, and confidentiality assurance. Participants were considered to have diabetes $(n=85)$ if they were undergoing medical treatment with hypoglycemic agents or insulin injections (self-reported) (12).

Study Design. This investigation is based on a cross-sectional population-based study in Portugal. All participants were asked to answer several questions regarding their physical activity and health. PA was assessed using the Portuguese validated version International Physical Activity Questionnaire short form (IPAQ) (13), which estimates PA across a comprehensive set of factors to yield a score in metabolic equivalents (METS)-minutes. Attendance in different SE programs was evaluated using a 3-point Likert scale (rarely - sometimes - often), across three kinds of PA programs providers: gym/healthclubs; swimming pools and another club/sports facilities. Measures for PA barriers were adapted from Thomas et al. (14). Items like the intention to participate in PA programs and the importance of the structure were evaluated by a 5-point Likert scale. PA information sources were evaluated using the scales by Pinheiro et al. (15). An expert panel of professors and researchers not involved in the study reviewed all items to ensure content and face validity. The board consisted of two sports scientists (with research experience), one expert researcher on market studies and survey development and one expert researcher on knowledge management. Fieldwork supervisors conducted a pre-test of the questionnaire with a sample of 25 individuals to ensure clarity and completion time.

Data Collection. Final data were collected by nine researchers (post-graduate students) after attending a 10 hours training course.

Statistical Analysis. We used independent ttests to examine the difference between the group means, and Levene's test to check the homokedasticity of the groups' variances.

\section{RESULTS}

Supervised vs. Self-selected PA among Diabetic and Non-diabetic. Regarding PA level assessed through IPAQ, diabetics (32\% low; 25\% moderate and $44 \%$ high) and non-diabetics (29\% low; $33 \%$ moderate and $39 \%$ high) display no statistically significant differences. Diabetics show a higher prevalence of lower and higher PA level. This result may suggest the existence of two behaviours among diabetics: a more active one, already engaged in PA routines and a more sedentary one $(32 \%)$ which does not meet PA recommendations.

Although $69 \%$ of diabetics report moderate or high physical activity, it is mostly unsupervised exercise since they do not attend sports facilities as shown in Table 1. Results show that both diabetics and non-diabetics opt by self-selected physical activity over SE. No significate differences were found between groups.

Table 1. Attendance of Sport Facilities

\begin{tabular}{|c|c|c|c|c|}
\hline & Rarely & Sometimes & Often & $\chi^{2}$ \\
\hline Do you attend a Swimming pool? & & & & 1.488 \\
\hline Diabetic & $88 \%$ & $2 \%$ & $10 \%$ & \\
\hline Non-diabetic & $86 \%$ & $5 \%$ & $8 \%$ & \\
\hline Do you attend any Gym/Health-club? & & & & 1.894 \\
\hline Diabetic & $94 \%$ & $1 \%$ & $5 \%$ & \\
\hline Non-diabetic & $91 \%$ & $4 \%$ & $5 \%$ & \\
\hline Do you attend any other club/sports facilities to do some physical activity? & & & & 1.173 \\
\hline Diabetic & $90 \%$ & $2 \%$ & $8 \%$ & \\
\hline Non-diabetic & $86 \%$ & $5 \%$ & $9 \%$ & \\
\hline
\end{tabular}

$\mathrm{P}<95 \%, \mathrm{DF}=2$, Significative if $>5.991$

When asked about the reasons for nonparticipation in SE programs the diabetic place more importance on the feeling that the exercise is not adequate to their health (Table 2). This is an exciting result as it suggests that when considering existing exercise programs, diabetics have a perception that they are not suitable for their health condition. From Table 2 it is important to point out that diabetics report a lower preference for autonomous exercise, which may mean that they would be more open for SE. Lack of time and activity schedules are factors more valued by nondiabetics than by diabetics, showing that diabetics are in some way available for exercise. 
Table 2. Causes of Non-participation in Supervised Exercise Programs

\begin{tabular}{|lccccccc|}
\hline & $\begin{array}{c}\text { Levene's } \\
\text { The activities are not interesting }\end{array}$ & $\mathbf{F}$ & $\begin{array}{c}\text { Levene's } \\
\text { p-value }\end{array}$ & $\begin{array}{c}\text { Mean } \\
\text { Diabetic }\end{array}$ & $\begin{array}{c}\text { Mean } \\
\text { No- } \\
\text { diabetic }\end{array}$ & t & $\begin{array}{c}\text { tf } \\
\text { t-test's } \\
\text { p-value }\end{array}$ \\
Price & .437 & .509 & 2.933 & 2.798 & .784 & 424.0 & .433 \\
The exercise is not adequate to my health & 3.905 & .049 & 2.853 & 3.076 & -1.084 & 102.3 & .253 \\
Distance & 1.356 & .245 & 2.853 & 2.437 & 2.308 & 423.0 & $.021 *$ \\
Lack of time & .828 & .363 & 2.773 & 2.581 & .982 & 424.0 & .327 \\
Other things to do & .611 & .435 & 2.684 & 3.220 & -2.721 & 108.5 & $.007 *$ \\
Type of participants & .016 & .899 & 2.680 & 2.955 & -1.495 & 11.8 & .136 \\
Participation cloud be dangerous to my health & .751 & .387 & 2.568 & 2.602 & -.194 & 103.2 & .846 \\
Schedule & .056 & .814 & 2.533 & 2.278 & 1.412 & 422.0 & .159 \\
Laziness/ Lethargy & .000 & .989 & 2.520 & 2.946 & -2.294 & 113.3 & $.022 *$ \\
Participation brings few benefits & .000 & .995 & 2.500 & 2.529 & -.155 & 109.6 & .877 \\
Lack of transportation & .719 & .397 & 2.453 & 2.314 & .822 & 42.0 & .412 \\
Teacher training methodology & 2.992 & .084 & 2.405 & 2.137 & 1.524 & 423.0 & .128 \\
I prefer doing self-select exercise & .311 & .577 & 2.267 & 2.632 & -2.045 & 112.6 & $.041 *$ \\
\hline
\end{tabular}

Significance level $=0.05$

PA Information Sources used. Considering that both diabetics and non-diabetics embrace self-selected physical activity over SE, it is crucial to evaluate what are PA information sources used by diabetics and non-diabetics (Table 3).

Results show that doctors are the preferred source of information with diabetics giving more importance to doctors than the no-diabetic. Diabetics rely less on information provided by the Internet and sports professionals. These results emphasize the fact that diabetics recognize neither the importance nor the advantages of exercise supervised by specialized professionals.
It is also verified that the higher means for information source preference were reported by both groups for doctors followed by friends and family (Table 3).

Intention to Participate in Different Types of Pre-defined Programs. Aware of the general low attendance of participation in existing SE programs, the researchers created seven hypothetical scenarios where different conditions (indoor/outdoor, alone/with friends, paid/free, family participation, organized by social media online) were provided to assess the willingness to participate in SE programs. The results are reported in Table 4.

Table 3. Information Sources about PA

\begin{tabular}{|lccccccc|}
\hline & $\begin{array}{c}\text { Levene's } \\
\mathbf{F}\end{array}$ & $\begin{array}{c}\text { Levene's p- } \\
\text { value }\end{array}$ & $\begin{array}{c}\text { Mean } \\
\text { Diabetic }\end{array}$ & $\begin{array}{c}\text { Mean No- } \\
\text { diabetic }\end{array}$ & $\begin{array}{c}\text { t } \\
\text { df }\end{array}$ & $\begin{array}{c}\text { t-test's p- } \\
\text { value }\end{array}$ \\
My doctor & 11.814 & .001 & 3.965 & 3.148 & 5.611 & 481.000 & $.000^{*}$ \\
Friends/family & 1.392 & .239 & 2.940 & 3.114 & -1.236 & 114.925 & .217 \\
Government awareness campaigns & 1.078 & .300 & 1.833 & 2.061 & -1.606 & 126.352 & .109 \\
The Internet sites & 9.294 & .002 & 1.607 & 1.977 & -2.969 & 141.652 & $.010^{*}$ \\
Teacher - school & 9.455 & .002 & 1.583 & 1.842 & -2.106 & 139.747 & .063 \\
The Internet social media & 7.847 & .005 & 1.464 & 1.694 & -2.039 & 133.946 & .063 \\
The TV & 1.570 & .211 & 2.298 & 2.562 & -1.790 & 125.067 & .074 \\
A sports professional & 1.310 & .253 & 2.286 & 2.680 & -2.332 & 127.977 & $.020^{*}$ \\
Newspaper/magazines & .006 & .936 & 2.235 & 2.472 & -1.559 & 122.889 & .120 \\
\hline
\end{tabular}

Diabetics value exercising with the family, as well as activities organized by primary health care (health centres).

Outdoor programs are not attractive to diabetics, and the presence of friends is more important for non-diabetics. The cost does not seem to be a crucial factor for participation in SE programs.

Importance of the Characteristics of the Structure that Hosts the Exercise Program. In order to call diabetics for the structures that host the SE programs, it is foremost to evaluate the characteristics perceived as more important for diabetics, and if these differ from those chosen by non-diabetics (Table 5).

Facilities seem to be very important for the practice of exercise. Diabetics value the presence of specialists that can deal with the disease, whereas they care less about the equipment, the innovative activities and meet other participants. It also should be noticed that there is no difference between diabetic and no-diabetic on the 
importance given to the presence of a doctor or a nurse, nor the degree of the fitness instructor.
These two items are valued by two groups, but diabetics present a lower mean.

Table 4. Intention to Participate in Supervised Exercise Programs

\begin{tabular}{|c|c|c|c|c|c|c|c|}
\hline I would participate in an exercise program if & $\begin{array}{l}\text { Levene's } \\
\quad \mathrm{F}\end{array}$ & $\begin{array}{l}\text { Levene's } \\
\text { p-value }\end{array}$ & $\begin{array}{l}\text { Mean } \\
\text { Diabetic }\end{array}$ & $\begin{array}{c}\text { Mean } \\
\text { No- } \\
\text { diabetic }\end{array}$ & $t$ & df & $\begin{array}{c}p- \\
\text { value }\end{array}$ \\
\hline that allowed the whole family to participate and had free entry & 0,008 & 0,930 & 3,229 & 3,385 & $-0,979$ & 116,689 & 0,328 \\
\hline that is organized by the Health Centre at no cost to the user & 0,594 & 0,441 & 3,120 & 3,213 & $-0,573$ & 121,947 & 0,567 \\
\hline $\begin{array}{l}\text { that was organized in the gardens / parks of my locality and } \\
\text { had free entrance }\end{array}$ & 1,428 & 0,233 & 2,976 & 3,205 & $-1,405$ & 122,694 & 0,161 \\
\hline that it was outdoors & 0,949 & 0,330 & 2,831 & 3,256 & $-2,682$ & 123,712 & $0,008^{*}$ \\
\hline that it was with my friends & 0,097 & 0,756 & 2,831 & 3,165 & $-2,140$ & 122,716 & $0,033^{*}$ \\
\hline I had a personal trainer coming to my house & 1,111 & 0,292 & 2,373 & 2,636 & $-1,560$ & 124,631 & 0,119 \\
\hline $\begin{array}{l}\text { that is organized through online social media, at no cost to the } \\
\text { user }\end{array}$ & 2,651 & 0,104 & 1,807 & 2,036 & $-1,556$ & 131,688 & 0,120 \\
\hline
\end{tabular}

Table 5. Importance of the Structure that Hosts the Exercise Program

\begin{tabular}{|c|c|c|c|c|c|c|c|}
\hline & $\begin{array}{l}\text { Levene's } \\
\quad \mathrm{F}\end{array}$ & $\begin{array}{l}\text { Levene's } \\
\text { p-value }\end{array}$ & $\begin{array}{l}\text { Mean } \\
\text { Diabetic }\end{array}$ & $\begin{array}{c}\text { Mean } \\
\text { No- } \\
\text { diabetic }\end{array}$ & $\mathbf{t}$ & df & $\begin{array}{l}\text { t-test's } \\
\text { p-value }\end{array}$ \\
\hline $\begin{array}{l}\text { Have specialists who know how to deal with my needs } \\
\text { (pathologies) }\end{array}$ & 1,073 & 0,301 & 3,929 & 4,005 & $-0,569$ & 115,884 & 0,569 \\
\hline Structure conditions (hygiene, furniture, equipment type ...) & 1,347 & 0,246 & 3,893 & 4,070 & $-1,451$ & 113,170 & 0,147 \\
\hline Localization & 0,566 & 0,452 & 3,741 & 3,681 & 0,416 & 481,000 & 0,678 \\
\hline Price & 5,798 & 0,016 & 3,718 & 3,819 & $-0,613$ & 111,914 & 0,499 \\
\hline Have good equipment & 9,997 & 0,002 & 3,690 & 3,960 & $-1,877$ & 107,150 & $0,032 *$ \\
\hline $\begin{array}{l}\text { Have evaluation parameters (measure heart rate and blood } \\
\text { pressure) }\end{array}$ & 0,464 & 0,496 & 3,607 & 3,602 & 0,035 & 116,869 & 0,972 \\
\hline Have doctor / nurse & 0,895 & 0,345 & 3,459 & 3,529 & $-0,475$ & 117,583 & 0,635 \\
\hline The fitness instructor has a degree in Sports Science & 0,219 & 0,640 & 3,369 & 3,605 & $-1,575$ & 119,642 & 0,116 \\
\hline Type of innovative activities & 0,322 & 0,571 & 3,143 & 3,451 & $-2,211$ & 117,320 & $0,027 *$ \\
\hline $\begin{array}{l}\text { Have another type of services (restaurant / bar, hairdresser, } \\
\text { dance classes, nutritional advice,...) }\end{array}$ & 1,344 & 0,247 & 2,893 & 2,861 & 0,204 & 477,000 & 0,839 \\
\hline Meet other participants & 2,715 & 0,100 & 2,786 & 3,111 & $-2,266$ & 115,885 & $0,024 *$ \\
\hline
\end{tabular}

\section{DISCUSSION}

Physical activity is a crucial element in the prevention and management of diabetes $(16,17)$, but its effectiveness and risk management require professional supervision $(8,10,11,18)$. Previous research $(2,3,12)$, also suggests that diabetics are reluctant to embrace SE programs. This evidence calls for actions to communicate the benefits of PA among diabetics better to stimulate their adherence to PA structured programs. For effectively achieve this goal it is essential to understand what diabetics think and feel, and what are the specific barriers preventing searching for information and engaging in physical activities when compared to the nondiabetic population.
Regarding physical activity level, the IPAQ score was not significantly different between patients with and without diabetes. Iwasa et al. (12) reported the same result. Results draw attention to $32 \%$ of diabetics are physically inactive, with all the health consequences that this situation carries out (17). Similar results were reported by Duarte et al. (19) where $31 \%$ of patients with type II Diabetes scored "low" in IPAQ. Our results on IPAQ scores, aligned with literature, reinforce the need to promote PA among Portuguese diabetic population.

Almost two-thirds of our diabetic sample presented a moderate or high level of PA. Nolan et al. (20) found a lower result (49\%), 
nevertheless, despite many respondents' being physically active, their activities did not have enough intensity to promote benefits in glycemic control. Despite diabetics' PA level, the attendance to SE programs is minimal what may indicate that exercise performed is not adequate to promote the benefits on diabetic control.

This lack of adherence is disadvantageous to diabetics themselves, as they do not take advantage of the benefits that PA could provide, not only in Diabetes management but also to improve their general physical condition $(21,22)$. Self-Selected PA tends to be performed at lower intensities and not so often, which impairs the physiological stimulus that the exercise produces (23). On the other hand, autonomous exercise does not consider a strategy to minimize the existing risks, which may generate dangerous situations for diabetics (7).

Both supervised and autonomous exercise show benefits to the health status in diabetics (18, $24)$, but SE is more effective $(8,10,11,25)$. The low adherence of diabetics to SE is also a missed business opportunity by the facilities hosting these programs.

Providing stable and trusty evidence of the benefits and the low risk associated with the SE for diabetics is crucial to surpass the significant barrier stated by them, which was the perception that exercise is not adequate to their health condition (Table 2). This finding may justify diabetics low-level of participation in these programs, and also reveals deficiencies in the communication between the structures that host the programs and diabetics, to show that they have professionals and methods for adapting PA exercises to the unique characteristics of each participant. The literature states that people with diabetes do not have enough information to take concrete actions to modify sedentary behavior and need better education and more information regarding the benefits of SE (2).

Since most diabetics perform self-selected PA, it is essential to evaluate where they obtain information about exercise (Table 3). Results show that diabetics undoubtedly prefer doctors as an information source. Similar results are presented in the literature $(3,26,27)$. This result underpins that any PA promotional campaign target to diabetics must involve first care providers and medical personnel, reinforcing previous indications that health professionals are the first to recommend the adoption of new dietary and exercise behaviors among diabetics (26). It is important to highlight that online campaigns (including the ones using social media) seem to be very limited, regarding the low audience reported. The present investigation is based on "real world" people, meaning they were not engaged in any intervention program, whereas literature often evaluates the effect of online interventions considering a particular (target) group (28). This distinctiveness may explain why those studies report higher use of social media as a PA information source, in contrast with our results.

The non-diabetics consistently reported receiving more information about physical activities programs. Noticeably, in line with previous research (27), current results show that doctors and family and friends are the best channels to convey PA information to diabetics. Results from non-diabetics are similar. Therefore, focusing the communication efforts primarily upon these two channels will be a winning bet. Additionally, it can be concluded that activities promoted by primary care centres, supported by the family and close friends could provide additional motivation and make the difference in increasing the attendance to physical activities events and programs by diabetics. These are precisely the major findings reported in Table 4, alongside in the importance of having "free entry," stressing the importance of the price factor. For that, it is recommended that these two aspects should always be included in any communication strategy and that the price must be set at a level that will not demotivate potential participants. Overall, both groups desire to have right conditions and equipment, and adequate counselling and monitoring while exercising. The two groups differ on the importance given to meeting other participants, innovative activities and having good equipment, which seems to be more critical to non-diabetics.

The instrument resulting from the adaptation of several questionnaires not extensively used is the main limitation and makes it difficult to compare results with previous studies. Also, the age range included a large variation of the characteristics of the diabetics interviewed, especially in the mental and physical characteristics, what may result in a limitations, when analysing all sample. These factors may condition the results obtained. 


\section{CONCLUSIONS}

Based on the findings, and addressing the objectives, both diabetics and non-diabetics reported a regular PA level (about two thirds with moderate or high level) but meagre participation in SE programs. Diabetics perceive that structured exercise is not adequate for their health, which is a significant barrier to participate in SE programs. This perception implies a lack of information on the benefits of SE and its advantages versus autonomous physical activities. Data results also reveal a gap between service providers (gym/health club/sport facilities managers) and potential clients (diabetics). The risk associated with PA seems to be an essential issue mainly among diabetics, and that is the reason why they rely mostly on the information provided by doctors, and people they trust. In conclusion, physical activity is a critical factor in controlling diabetes, so its promotion in this group has been of particular importance. However, PA may not provide enough stimuli to provide physiological changes that improve glycaemic balance, if not performed with adequate individualized goals (intensity, type, volume).

\section{APPLICATIONS REMARKS}

- The Fitness trainers and instructors must improve the exercise programs for diabetics not only to design specific exercises but also to minimize exercise risks.

- The promoters of PA programs such as gyms or health clubs should implement supervised exercises programs for diabetics as it can help to attract diabetics for their services.

\section{REFERENCES}

1. Colberg SR, Sigal RJ, Yardley JE, Riddell MC, Dunstan DW, Dempsey PC, et al. Physical Activity/Exercise and Diabetes: A Position Statement of the American Diabetes Association. Diabetes Care. 2016;39(11):20652079. doi: 10.2337/dc16-1728 pmid: 27926890

2. Jenkins DW, Jenks A. Exercise and Diabetes: A Narrative Review. J Foot Ankle Surg. 2017;56(5):968-974. doi: 10.1053/j.jfas.2017.06.019 pmid: 28842107

3. van der Berg JD, Stehouwer CD, Bosma H, van der Velde JH, Willems PJ, Savelberg HH, et al. Associations of total amount and patterns of sedentary behaviour with type 2 diabetes and the metabolic syndrome: The Maastricht Study. Diabetologia. 2016;59(4):709-718. doi: 10.1007/s00125-015-3861-8 pmid: 26831300

4. Arena R, Sagner M, Byrne NM, Williams AD, McNeil A, Street SJ, et al. Novel approaches for the promotion of physical activity and exercise for prevention and management of type 2 diabetes. Eur J Clin Nutr. 2017;71(7):858-864. doi: 10.1038/ejen.2017.53 pmid: 28443607

5. Asif M. The prevention and control the type-2 diabetes by changing lifestyle and dietary pattern. J Educ Health Promot. 2014;3:1. doi: 10.4103/2277-9531.127541 pmid: 24741641

6. Olson EA, McAuley E. Impact of a brief intervention on self-regulation, self-efficacy and physical activity in older adults with type 2 diabetes. J Behav Med. 2015;38(6):886-898. doi: 10.1007/s10865-015-9660-3 pmid: 26162648

7. Pedersen BK, Saltin B. Exercise as medicine - evidence for prescribing exercise as therapy in 26 different chronic diseases. Scand J Med Sci Sports. 2015;25 Suppl 3:1-72. doi: 10.1111/sms.12581 pmid: 26606383

8. Umpierre D, Ribeiro PA, Kramer CK, Leitao CB, Zucatti AT, Azevedo MJ, et al. Physical activity advice only or structured exercise training and association with HbA1c levels in type 2 diabetes: a systematic review and meta-analysis. JAMA. 2011;305(17):1790-1799. doi: 10.1001/jama.2011.576 pmid: 21540423

9. Balducci S, Zanuso S, Cardelli P, Salvi L, Bazuro A, Pugliese L, et al. Effect of high- versus low-intensity supervised aerobic and resistance training on modifiable cardiovascular risk factors in type 2 diabetes; the Italian Diabetes and Exercise Study (IDES). PLoS One. 2012;7(11):e49297. doi: 10.1371/journal.pone.0049297 pmid: 23185314

10. Ried-Larsen M, MacDonald CS, Johansen MY, Hansen KB, Christensen R, Almdal TP, et al. Why prescribe exercise as therapy in type 2 diabetes? We have a pill for that! Diabetes Metab Res Rev. 2018;34(5):e2999. doi: 10.1002/dmrr.2999 pmid: 29488311

11. Grace A, Chan E, Giallauria F, Graham PL, Smart NA. Clinical outcomes and glycaemic responses to different aerobic exercise training intensities in type II diabetes: a systematic review and meta-analysis. Cardiovasc Diabetol. 2017;16(1):37. doi: 10.1186/s12933-017-0518-6 pmid: 28292300

12. Iwasa T, Amiya E, Ando J, Watanabe M, Murasawa T, Komuro I. Different Contributions of Physical Activity on Arterial Stiffness between Diabetics and Non-Diabetics. PLoS One. 2016;11(8):e0160632. doi: 10.1371/journal.pone.0160632 pmid: 27508936 
13. Craig CL, Marshall AL, Sjostrom M, Bauman AE, Booth ML, Ainsworth BE, et al. International physical activity questionnaire: 12-country reliability and validity. Med Sci Sports Exerc. 2003;35(8):1381-1395. doi: 10.1249/01.MSS.0000078924.61453.FB pmid: 12900694

14. Thomas N, Alder E, Leese GP. Barriers to physical activity in patients with diabetes. Postgrad Med J. 2004;80(943):287-291. doi: 10.1136/pgmj.2003.010553 pmid: 15138320

15. Pinheiro P, Esteves D, Brás R. Effect of Internet and social networks on knowledge regarding physical activity. Int J Manag Sci Inf Technol. 2012(4-(Apr-Jun)):29-41.

16. Colberg SR, Sigal RJ, Fernhall B, Regensteiner JG, Blissmer BJ, Rubin RR, et al. Exercise and type 2 diabetes: the American College of Sports Medicine and the American Diabetes Association: joint position statement. Diabetes Care. 2010;33(12):e147-167. doi: 10.2337/dc10-9990 pmid: 21115758

17. Sabag A, Way KL, Keating SE, Sultana RN, O'Connor HT, Baker MK, et al. Exercise and ectopic fat in type 2 diabetes: A systematic review and meta-analysis. Diabetes Metab. 2017;43(3):195-210. doi: 10.1016/j.diabet.2016.12.006 pmid: 28162956

18. Dadgostar H, Firouzinezhad S, Ansari M, Younespour S, Mahmoudpour A, Khamseh ME. Supervised groupexercise therapy versus home-based exercise therapy: Their effects on Quality of Life and cardiovascular risk factors in women with type 2 diabetes. Diabetes Metab Syndr. 2016;10(2 Suppl 1):S30-36. doi: 10.1016/j.dsx.2016.01.016 pmid: 26822461

19. Duarte CK, Almeida JC, Merker AJ, Brauer Fde O, Rodrigues Tda C. Physical activity level and exercise in patients with diabetes mellitus. Rev Assoc Med Bras (1992). 2012;58(2):215-221. pmid: 22569617

20. Nolan RC, Raynor AJ, Berry NM, May EJ. Self-Reported Physical Activity Using the International Physical Activity Questionnaire (IPAQ) in Australian Adults with Type 2 Diabetes, with and Without Peripheral Neuropathy. Can J Diabetes. 2016;40(6):576-579. doi: 10.1016/j.jcjd.2016.05.013 pmid: 27658764

21. Fennell C. Effects of Supervised Training Compared to Unsupervised Training on Physical Activity, Muscular Endurance, and Cardiovascular Parameters. MOJ Orthoped heumatol. 2016;5(4). doi: 10.15406/mojor.2016.05.00184

22. Lacroix A, Hortobagyi T, Beurskens R, Granacher U. Effects of Supervised vs. Unsupervised Training Programs on Balance and Muscle Strength in Older Adults: A Systematic Review and Meta-Analysis. Sports Med. 2017;47(11):2341-2361. doi: 10.1007/s40279-017-0747-6 pmid: 28573401

23. Chen CN, Chuang LM, Korivi M, Wu YT. Home-based exercise may not decrease the insulin resistance in individuals with metabolic syndrome. J Phys Act Health. 2015;12(1):74-79. doi: 10.1123/jpah.2013-0284 pmid: 24509907

24. Mazzuca P, Montesi L, Mazzoni G, Grazzi G, Micheli MM, Piergiovanni S, et al. Supervised vs. self-selected physical activity for individuals with diabetes and obesity: the Lifestyle Gym program. Intern Emerg Med. 2017;12(1):45-52. doi: 10.1007/s11739-016-1506-7 pmid: 27424279

25. Mosalman Haghighi M, Mavros Y, Fiatarone Singh MA. The Effects of Structured Exercise or Lifestyle Behavior Interventions on Long-Term Physical Activity Level and Health Outcomes in Individuals With Type 2 Diabetes: A Systematic Review, Meta-Analysis, and Meta-Regression. J Phys Act Health. 2018;15(9):697707. doi: 10.1123/jpah.2017-0589 pmid: 29741425

26. Plotnikoff RC, Johnson ST, Karunamuni N, Boule NG. Physical activity related information sources predict physical activity behaviors in adults with type 2 diabetes. J Health Commun. 2010;15(8):846-858. doi: 10.1080/10810730.2010.522224 pmid: 21170787

27. Sanchez A, Bully P, Martinez C, Grandes G. Effectiveness of physical activity promotion interventions in primary care: A review of reviews. Prev Med. 2015;76 Suppl:S56-67. doi: 10.1016/j.ypmed.2014.09.012 pmid: 25263343

28. Connelly J, Kirk A, Masthoff J, MacRury S. The use of technology to promote physical activity in Type 2 diabetes management: a systematic review. Diabet Med. 2013;30(12):1420-1432. doi: 10.1111/dme.12289 pmid: 23870009 